\title{
A Case Study Exploring Coaching Practice and Coaching Perspectives at One Soccer (Football) Club
}

\author{
Karagiannis Konstantinos ${ }^{1}$ \\ Pill Shane ${ }^{2 *}$ \\ 1,2 Flinders University, School of Education, GPO Box 2100, Adelaide, 5001, Australia
}

Keywords: football (soccer), coaching, game sense approach

\begin{abstract}
This study investigated the extent to which three local club football (Soccer) coaches were aligning their practice with the Football Federation Australia (FFA) curriculum and if they are aware of and incorporating the Game Sense coaching methods advocated by the Australian Sports Commission through the Playing for Life Philosophy. There is currently a lack of research in the sport of Soccer and how the Game Sense coaching approach has been received and understood in Australian Soccer coaching. Further, the degree of alignment club coaches have with the FFA curriculum has only been investigated once, and that was in Sydney. Therefore, little is known about the implementation of the FFA curriculum in community coaching settings. This study found the three coaches to have good understanding of the mechanics of the FFA curriculum, and support for the use of small-sided games as a preferred practice form. The coaches had no understanding of the process of shaping and focussing player game development using the player-centred inquiry focus of the Game Sense approach.
\end{abstract}

\section{Introduction}

This research investigated whether local club Soccer coaches are aligning their practice with the Football Federation Australia (FFA) curriculum (Berger, 2013) and if they are aware of and incorporating the Game Sense approach (GSA) coaching methods (Den Duyn, 1997) advocated by the Australian Sports Commission (ASC) through the Playing for Life Philosophy (Australian Sports Commission, 2016).

This research analysed whether the current FFA curriculum (Berger, 2013) is having an influence at a local level on coaches at one Soccer club, and if applied in the intended way to develop players' skills and knowledge of the game. This study was therefore a case study at one club.

There has been a lack of research into whether local coaches are aligning their coaching practice with the FFA curriculum (Berger, 2013). There have been

\footnotetext{
*E-mail: shane.pill@flinders.edu.au
} 
studies where the GSA is analysed in different sports (Light \& Evans, 2013; Pill, 2015; Light \& Robert, 2010); however, there is a lack of research into this coaching approach in the sport of Soccer (Football) in Australia.

Most studies that have occurred focused on elite teams and coaches. In comparison, this study addresses the gap in understanding what is occurring at community level coaching by considering local semi-professional Soccer coaches. There has been previous research into the education of coaches in England and Canada (Holt, 2002) which will inform this study. It is also relevant to consider the underlying philosophy of Australian sport espoused by the ASC (2016), the Playing for Life Philosophy, because it has been closely associated with the GSA (Den Duyn, 1997), and is meant to inform coach education and coaching curriculum documents in Australia.

The Playing for Life philosophy is based on the GSA core principles (ASC, 2016; Ling, Farrow, Farrow, Berry, \& Polman, 2016). This philosophy and the GSA (Den Duyn, 1997) of coaching is posited that when used with players aids development of the technical and tactical skills to play sport more effectively than traditionally more common coaching practices based on directive instruction and ‘drill’ practice (ASC, 2016; Den Duyn, 1997; Light, 2013).

The GSA provides coaches with a pedagogical framework that is proposed as more likely to provide positive sporting experiences from which develop a positive attitude towards sport and a lifelong interest in physical activity (Ling et al., 2016). The GSA directs coaches to greater use of games as a way of teaching technical skills and tactics of a particular sport in unison, rather than a traditional drill practice style of coaching that separates tactical and technical components of training into separate sections of the training plan.

This sport-coached as-techniques, or 'drill' approach, involves isolating the individual skill and practicing it in a drill format, whereby players progress from basic to complex motor skill patterns in practice tasks focusing on learning the 'correct' technique (Pill, 2013). Once the 'correct' technique is achieved the technical motor skills learned in isolation from the game are then put back into a game format (Pill, 2016). In comparison, when coaching using a GSA, the activities and games carried out are mostly game-based or 'game-like', which it is asserted develops technical skills and tactical knowledge while more likely enjoying the sport practice experience (Den Duyn, 1997; Pill, 2016).

To achieve the ambition of 'thinking players' (Den Duyn, 1997), the coaches' role is viewed as a facilitator to set challenges to be solved preferentially in game play rather than directing solutions through command style instruction (Ling et al., 2016). Discrete coaching is still part of the GSA, but keeping instructions and demonstrations to a minimum is advocated and coaches are challenged to think about when it is the right time for an isolated from the game practice task and to think 'game-first' or 'play first' when planning practice so more game play is had. The coach asking thought provoking questions to engage players tactical thinking, and activity scaling to be more or less challenging based on 'learner need' are other elements featured in a GSA (ASC, 2016; Light, 2013; 
Ling et al., 2016). Not surprisingly then, informed by the GSA (ASC, 2016) the Playing for Life Philosophy key principles are keeping the game as the focus, to challenge players to think about what they are doing, and why they are doing it.

The Game Sense Coaching Approach

Pill (2015) noted that 'game sense' was a term used in 1969 by Thorpe and West as a way of describing game intelligence and a way of assessing game performance. Australian Hockey coach Rick Charlesworth also mentioned game sense in 1993, using the term to describe a player development outcome of Designer Games (Charlesworth, 1993). Launder (2001) similarly uses game sense as a synonym for game intelligence, one of the several player learning outcomes he describes arising from quality coaching pedagogy.

In Australia, the GSA is more commonly known as a coaching derivative of Teaching Games for Understanding (TGfU) (Bunker \& Thorpe, 1982). TGfU is a pedagogical model for physical education that was developed as an alternative to teaching game skills as techniques in isolated and repetitive drill practice environments, that arguably resulted in poor decision-making, poor tactical awareness and an inability to reproduce learnt skills in a game setting (Bunker \& Thorpe, 1982; Light, 2013). The TGfU 'game-based' teaching idea was refined in the mid 1990's through Rod Thorpe's work with the Australian Sports Commission to develope a game-based and player-centred approach to coaching called the GSA (Den Duyn, 1996; Light, 2013; Pill, 2015).

In contrast to a directive 'skill-drill' approach with a focus on improving technical skills through practice repetition and isolation from the game context the GSA focuses on the learning being 'player centred'. This is evident by the coach asking questions in preference to predominantly giving instructions, and by training "skills" - defined as the combination of tactical and technical components, preferably in a game context. This method of coaching is argued as allowing players to practice their skills in the same complex and dynamic environment of a game (Pill, 2015) to develop real game competency as what is learnt in training is more likely to transfer to play due to the more representative environment at practice (Den Duyn, 1997; Light, 2013; Pill, 2013, 2015). The GSA is thus focused on teaching sports in a whole (game)-part (practice)-whole (game) method (Reid, 2003) typical of a 'tactical' instructional model (Metzler, 2011) rather than using a step-by-step 'progressive part' model.

Wein (2004) proposed a model very similar to the GSA, 'game intelligence'. Game intelligence is the knowledge of the game that one possesses, which allows a player to quickly recognise and adapt to a situation in a game (Wein, 2004). Similar to the central premise of the GSA - developing thinking players, (Wein, 2004) proposed the game intelligence of a player should be the real driving force behind their performance, as generally, a players game intelligence will explain success and be the difference between one player and another's action competencies in the game. Internationally it is recognised that to develop Soccer skill a systematic development of thinking and tactical awareness needs to from the 
developmental model for the sport (Cross, 2013; Launder, 2001; Light, 2013; Wein, 2004), which in Australia is called the ‘curriculum' (FFA, 2016).

\section{The FFA Approach}

The FFA has a vision and philosophy of a proactive brand of Soccer being played in Australia, based on effective possession with the cutting edge provided by creative individuals (Berger, 2013). Proactive Soccer is playing Soccer with an attacking focus with the primary objective being to score goals, whereas a reactive style of Soccer is playing with a defensive focus and only attacking on the counter attack (Cross, 2013). Effective possession involves not just having the ball, but being able to use the possession to break down the opposition to get into goal scoring opportunities and score goals (Cross, 2013). This current curriculum and its underlying philosophy of Soccer is intended to help the FFA reach its ambitious long-term mission of making Australia a world leader in the "world" game (Cross, 2013).

The FFA curriculum proposes learning taken out of a game context is not an ideal as there are no 'game-specific' situations such as opponents (FFA, 2016). Learning skills in isolation does not satisfy the adage, 'practice as we want them to play'. The FFA curriculum suggest three phases of game need to be trained: these are perception, (seeing what is happening) decision (deciding what the best option is) and execution (performing the required skill) (FFA, 2016). Isolated training focusing only on the execution phase tends to ignore the perception and decision phases while practicing execution without relevance (FFA, 2016).

The FFA curriculum suggests practice as playing the game using the elements of perceiving, deciding and executing because this will develop game intelligence by putting players in situations where they are learning in contexts that will assist transfer of learning from practice to the game. A player centred focus is promoted to help improve players' skills and knowledge of the game (FFA, 2016). The FFA curriculum focus on game-based practice has obvious parallels with the GSA.

Of particular relevance to this study, research on Sydney metropolitan Soccer coaches by Siokos (2011) identified a need for an increase in coach education and training of small-sided Soccer and games in order for greater coach compliance with the tenets of the FFA curriculum (Siokos, 2011). Siokos (2011) found limited adherence to the coaching tenets of the FFA curriculum.

More broadly, literature has shown that coaches value and use games as an important element of training, and recognise the ways that small-sided games can develop game intelligence that cannot be taught through a skill-drill approach (Light \& Evans, 2011). However, in Australia the entire GSA pedagogy has not been completely understood as coaches still tend to adopt a directive teaching approach even when using games as a main training form. This seems to be because coaches lack knowledge on pedagogy in general, and lack knowledge of the GSA particular emphasis on inquiry and problem solving processes (Light \& Evans, 2011). 
Research surrounding the GSA exists in sports such as Australian Football (Pill, 2015; Pill, 2016) and Rugby (Light \& Evans, 2011; Light \& Evans, 2013), however, there is a gap when it comes to soccer coaching research in Australia. There is some research into GSA application and Soccer internationally (Harvey, 2009; Harvey, Cushion, Wegis, \& Massa-Gonzalez, 2010). This research is focused on either school settings (Harvey et al., 2010; Jarrett, 2011) or elite level athletes (Light, 2004) Therefore, there is a gap in the knowledge of sub-elite coaching at a local or community club level.

\section{Material and methods}

The research methodology is informed by Crotty's (1998) methodological description. This research is interpretivist because within the approach taken in this study the researcher does not start with ideas already determined about the outcomes, but rather seeks to allow these ideas to emerge from results in the field (Connole, 1993; Merriam, 2009). The interpretivist paradigm (Morgan, 2007) was applied to further explore local Soccer coaches' alignment and awareness of the FFA curriculum and the Playing for Life Philosophy's GSA to coaching with their current coaching practice. Although the interpretivist paradigm incorporates a few different paths of thought, it can be generally defined in terms of its basic assumption about the nature of research: that research is concerned with describing what meaning people bring to their experience (Connole, 1993; Merriam, 2009) and that opinions and views vary for each individual and between contexts (O’Donoghue, 2007).

This research used a qualitative theoretical perspective suitable for the exploratory nature of the study (Merriam, 1988). This perspective enabled an understanding of underlying reasons or opinions, and provides insights into a particular problem or helps to develop ideas and hypotheses for potential quantitative research (Merriam, 1998). A case study design was adopted as this was a study of coaches at one metropolitan Soccer club. The research questions were shaped from a previously published study (Siokos, 2011). A convenience sample strategy was used to select participants 'close at hand' and easy to access (Punch \& Oancea, 2009). Research Ethics Committee approval for the study occurred before data collection commenced.

\section{Data collection}

There were four data collection tools in this study; questionnaires, document analysis, face-to-face interviews and session observations. These were effective tools for data collection as the study questions required qualitative data. The questionnaires collected qualitative data on the coaches previous coaching experience, and information on their knowledge of the FFA curriculum (Cross, 2013) and the GSA (Den Duyn, 1997). The questions were based on Siokos (2011). The questionnaire was followed by face-to-face interviews. The interviews allowed the chief investigator (author 1) to gain further insight on the coaches' views and knowledge on the FFA curriculum and the GSA. The interviews were recorded 
using a voice recorder. During the interviews the chief investigator collected the coach's coaching plan for the year.

The coaching plans were collected to measure whether the planned coaching practice was aligning with the FFA curriculum and to gauge to what extent the GSA methods were being incorporated. Season plans were analysed for appropriateness and relevance to the age group of players. To further measure compliance and application of the FFA curriculum and the GSA, training sessions were observed chief investigator and the Active Learning Time (ALT) coding tool (Figure 1) was to code session in real time. The ALT tool measures how much time is spent on each of the following components of the practice session - movement time, physical activity time, feedback time and instruction time.

\section{Participants}

Three coaches from a local Soccer club in South Australia were invited to participate in the study, once the president of the Soccer club had approved the approach and the club engagement in the research. Informed consent and approval was gained from the three coaches to participate in the research. The participants were given pseudonyms so that they remain anonymous.

Table 1. ALT coding tool showing how data was coded and collected

\section{Team: XXXXX}

Date: $9 / 8 / 2016$

Lesson Length: 6:30p.m-8p.m (90 minutes)

Equipment: Stop watch

\section{Directions}

As soon as the class time is due to officially start the Observer begins to time the lesson. Throughout the lesson recordings are made of the time spent in the following teaching behaviours.

\footnotetext{
ST Length of time from the official session start time to the time when the teacher formally starts the lesson.

MT - Movement The amount of time students spend in movement to and from, and in between, Time each of the session activities.

IT - Instruction The amount of time students spend listening to coach instructions.

Time

IF - Individual The amount of time the coach spends giving feedback to specific students (IF) Feedback GF - or groups of students (GF).

Group Feedback

PAT - Physical The amount of time students spend being physically active in drills and game Activity Time play.

IQT - Inquiry The amount of time the coach spends using questions to stimulate student Time thinking, creativity and knowledge construction.

ALT - Active the amount of time the students spend engaged in learning (ALT = PAT + Learning Time IQT).

Time Session is Due to Start (Formal Start Time instructed by Coach) 6:30p.m be there 6:15 latest

ST

MT

IT

Team address 6:29, warm up commenced 6:30

Warm up completion to first drill - 20 seconds

First drill to second (drink included) - 1 minute

Second drill to Small sided game - 1 minute

Initial team address at start of session $-1: 10$ minute
} 


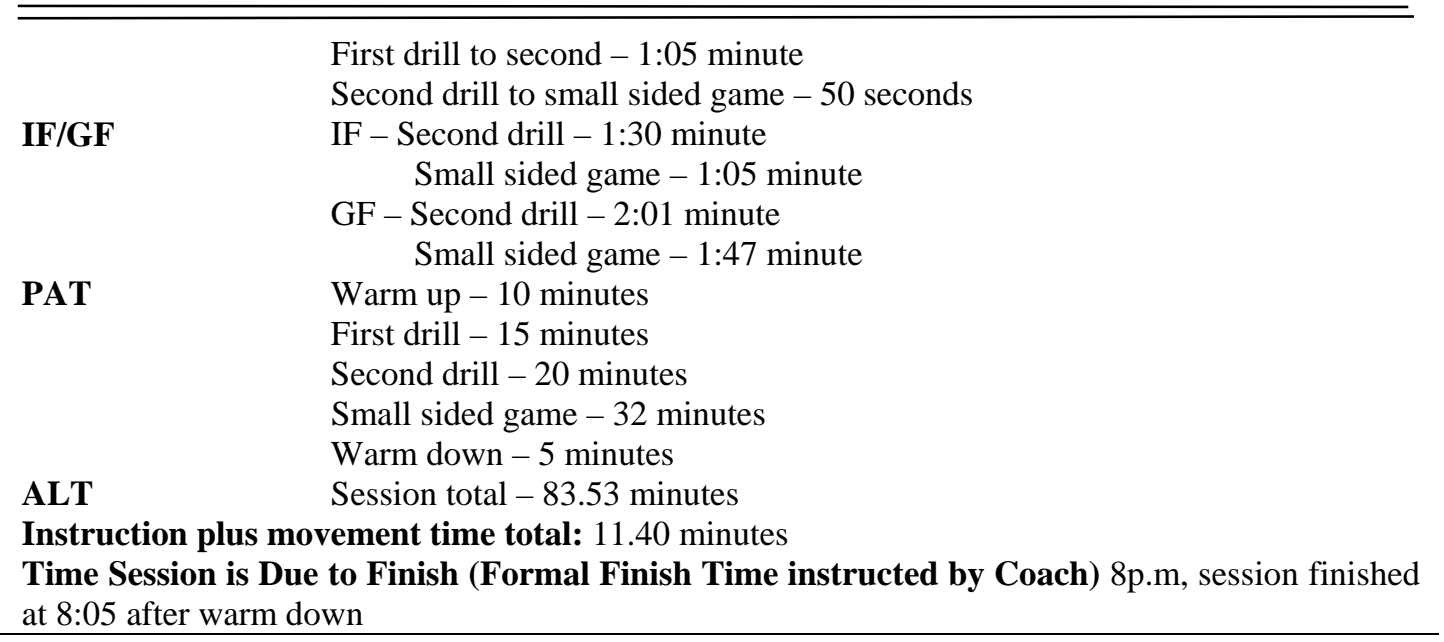

Data Analysis

The qualitative data was analysed according to themes. The three main themes: 1. FFA related data; 2. GSA related data; and 3. Planning related data. By collecting data on these themes, it allowed the researchers to have discussion points that would begin to answer the original research question. Each theme was designated a certain colour in order to code the interview transcripts, questionnaire answers, and coaching plans. Quantitative data was produced from the session observations, where the amount of time spent on each component of the session was shown and then further sorted into a percentage. When training sessions were observed, the ALT coding tool was used along with a stopwatch, which allowed the researcher to measure the amount of time spent on each part of the session. This data was recorded on a table with titles of each part of the session, such as movement time, active learning time and inquiry time (Figure 1).

\section{Results and Discussions}

The coaches stated that the FFA curriculum has been beneficial to them. As coaches are able to work from a framework or a platform, so they are able to build their yearly coaching plans. Coach 1 agreed with the FFA curriculum and appreciated how it has taught him to develop season plans, stating: "It has been an effective tool because it gives coaches some sort of platform to work off. Which helps with the development of players as there are structures in place to help this" (Coach 1, Interview, 9/8/2016).

It was evident the coaches felt the FFA Curriculum was a guide and not a framework to be followed verbatim. For example, Coach 1 also stated that "the FFA curriculum does not have to be followed word for word; it is simply a guide rather than a rule". Consistent with the FFA Curriculum, coaches used small-sided games a lot in their training, and all indicated that they were one of the most effective tools to help players develop, as players are more likely to gain more touches of the ball, and have to make quicker decisions in the smaller format of the game. In the interviews coaches discussed that there is now a more evident focus on the 'technical' ability of a player rather than the physical ability of the player as 
an athlete. The coaches liked this emphasis. This quote form Coach 2 summarised the general feeling:

"Yes I agree with the new curriculum and especially the small sided games aspect to coaching, because players are able to hone in on their technical ability and get more touches on the ball” (Coach 2, interview, 30/8/2016)

The coaches in this study found the FFA curriculum to be an effective guide for both players and coaches. Coach 1 was supportive of the new FFA curriculum focus, and said:

"I prefer the new coaching methods as it encourages more touches on the ball by players to make their own decisions when they play. This allows players to have to think about game situations a lot more, rather than just the skills used in the game. Players will then have a deeper understanding of the game, rather than just being able to execute the skills involved in Soccer" (Coach 1, Interview, 9/8/2016).

However, the coaches in this study were not aware of the GSA to coaching sport. The coaches enthusiastically adopted the used small-sided games. For example, Coach 3 stated, "I am not aware of the Game Sense approach to coaching; however I do use small-sided games in my coaching plans” (Coach 3, interview, 10/8/2016), and Coach 2 commented, "I am not really aware of the Game Sense approach to coaching” (Coach Two, Interview, 30/8/2016). The coach's descriptions of their coaching indicated some alignment with sport pedagogy of a GSA. For example, Coach 1 stated; "I incorporate small-sided games and use questioning afterwards to get the best out of players" (Coach 1, Interview 9/8/2016).

The two season plans adhered to the FFA curriculum. The plan had the correct six cycles required throughout the year, with each cycle focusing on one specific aspect of Soccer skill development within the team model. The six cycles started from the beginning of pre-season and continued through to the end of the season, this is a thorough plan to have in place. Each cycle is meant to have a Soccer specific focus (Cross, 2013), however, in the plans provided it was not specifically stated what Soccer specific focus there was in each cycle. There was a stronger focus on the fitness and its maintenance throughout the year. The season plans were quite specific in terms of the planned drills and exercises and shows the planning for each session, the duration and rest periods of exercises to indicate the workload in each cycle.

The alignment of coaches' season plans and what occurred during the observed training sessions was poor. A majority of time in the sessions occurred with players being physically active. The second highest percentage of time during the session was individual and group feedback. However, this was not pre-planned guided questioning but rather, appeared to be made-up as the session progressed. This potentially diluted the players' attention from the learning intention of the session as new foci were introduced. For example, the season plan for the period of observation for one group called for "big" games on a large pitch and "medium" games on a half pitch (calling these games by the size such as big, medium and small is part of the language of the FFA curriculum (Cross, 2013). However, in the 
session observed, only small-sided games on small pitches (such as the '18yard box' which is $40 \mathrm{~m}$ wide $\mathrm{x} 17 \mathrm{~m}$ long). While the coaching plans have included the correct FFA cycles (Cross, 2013) and therefore may appear to align with the FFA curriculum, however they were not observed to be implemented as is planned. None of the coaches had prepared individual session plans, and only referred back to the season plan, which could be why coaches seemed to drift away from the season plan.

With specific consideration of the GSA, the use of guided questioning is an integral pedagogical element of the GSA (Light, 2013), however, within the coach's season plans there were not pre-planned questions and any questions asked during the practice were ad-hoc created during the session. In the interviews the coaches all stated that they like to question leaners after activities, however, they were not observed to be are not doing this at training. The coding of training sessions showed that between $5-7.4 \%$ of the sessions was spent on individual and group feedback.

In summary, the coaches demonstrated comprehension of the mechanics of the FFA curriculum but were not always applying this knowledge to plan sessions or in practice sessions. The GSA has been established for roughly 20 years (Den Duyn, 1997) and yet the three coaches had limited knowledge about this approach and were not showing any understanding of it as a player centred pedagogy based on the use of questioning approaches to deliberately position the players as thinking players (Den Duyn, 1997).

\section{Conclusions}

There is a clear need for further research into community coaches understanding of contemporary game-based coaching pedagogy. If the ambition of the Australian Sports Commission development of the GSA (ASC, 1996) was to shift the sport pedagogy to a player-centred coaching style then the evidence from the coaches in this study is that there is still much to do in coach education and support to change practice at community club level. While the GSA has been shown to have a potentially positive impact on players and coaches when it has been implemented (Light, 2004; Harvey, 2009; Jarrett, 2011; Pill, 2015), recognition of the approach and its process was not evident in this study.

There is the need for more Soccer specific coaching research in Australia, to understand more fully what is happening in club coaching and to inform efforts to improve the standard of coaching and in turn Soccer players Australia develops. Apart from this study, only one study addressing the implementation of the FFA curriculum in Australia was found. It specifically addressed the use of small-sided games within Soccer coaching practice (Siokos, 2011). Collaborative action research, similar to that conducted in other sports: Australian football (Pill, 2015, Pill, 2016) and Rugby (Light \& Evans, 2011; Light \& Evans, 2013), should be encouraged by the FFA. Furthermore, it would be advantageous if the FFA curriculum was written to more obviously align to the ASC Playing for Life Philosophy and GSA approach so that coaches could see the association between 
the pedagogical desires of the FFA curriculum and the tenets of game based coaching.

\section{References}

1. AUSTRALIAN SPORTS COMMISSION. (2016). Playing For Life. Australian Government: Australian Sports Commission - Sporting Schools. Retrieved 29 June 2016, from https://www.sportingschools.gov.au/about/playing-for-life

2. BERGER, H. (2013). The National Football Curriculum "The Roadmap to International Success, Sydney South, NSW: Football Federation Australia;

3. BUNKER, D., \& THORPE, R. (Eds.). (1982). Reflecting on the teaching of games, Bulletin of Physical Education Themed Edition, 18 (1);

4. CHARLESWORTH, R. (1993). Hockey level 3 NCAS course - discussion topic: designer games, Melbourne, VIC: Hockey Australia;

5. CONNOLE, H. (1993). The research enterprise, In H. Connole, B. Smith \& $\mathrm{R}$. Wiseman (Eds.), Issues and methods in research: Study guide, Adelaide, SA: University of South Australia, 21-40;

6. CROSS, K. (2013). The football coaching process - an official FFA publication, Football Federation Australia;

7. CROTTY, M. (1998). The foundations of social research. London: Sage;

8. DEN DUYN, N. (1997). Coaching Children: Game Sense-It's Time to Play!, Sports Coach, 19: 9-11;

9. FOOTBALL FEDERATION AUSTRALIA. (2016). Coach Development Coach Development Overview. Football Federation Australia - Coaching Resource. Retrieved 25 May 2016, from http://www.ffacoachingresource.com.au/coach-development/coach development-overview/

10. HARVEY, S. (2009). A study of interscholastic soccer players perceptions of learning with game sense, Asian Journal of Exercise and Sport Science, 6(1): $1-10$;

11. HARVEY, S., CUSHION, C.J., WEGIS, H.M., \& MASSA-GONZALEZ, A.N. (2010). Teaching games for understanding in American high-school soccer: A quantitative data analysis using the game performance assessment instrument, Physical Education and Sport Pedagogy, 15(1): 29-54;

12. HOLT, N. (2002). A comparison of the soccer talent development systems in England and Canada, European Physical Education Review, 8(3), 270-285;

13. JARRETT, K. (2011). Undergraduate sports students' perceptions of a change to game sense pedagogy, Asian Journal of Sports Science, 8 (1): 1-17;

14. LAUNDER, A. (2001). Play practice, Champaign, IL: Human Kinetics;

15. LIGHT, R. (2004). Coaches' experiences of Game Sense: opportunities and challenges, Physical Education \& Sport Pedagogy, 9(2): 115-131;

16. LIGHT, R. (2013). Game sense: Pedagogy for performance, participation and enjoyment, New York, NY: Routledge; 
17. LIGHT, R., \& EVANS, J. (2011). The impact of Game Sense pedagogy on Australian rugby coaches' practice: a question of pedagogy, Physical Education \& Sport Pedagogy, 16(1): 101-101;

18. LIGHT, R., \& EVANS, J. (2013). Dispositions of elite-level Australian rugby coaches towards game sense: Characteristics of their coaching habitus, Sport, Education and Society, 18(3): 407-423;

19. LIGHT, R., \& ROBERT, J. (2010). The impact of game sense pedagogy on Australian rugby coaches' practice: A question of pedagogy, Physical Education and Sport Pedagogy, 15(2): 103-115;

20. LING, F., FARROW, A., FARROW, D., BERRY, J., \& POLMAN, R. (2016). Children's perspectives on the effectiveness of the Playing for Life philosophy in an afterschool sports program, International Journal of Sports Science \& Coaching, 11(6): 780-788;

21. MERRIAM, S. B. (1988). Case study research in education: A qualitative approach, San Francisco: Ca: Jossey-Bass;

22. MERRIAM, S. B. (2009). Qualitative Research: A guide to design and implementation, 2 ed., San Francisco: Ca: Jossey-Bass;

23. METZLER, M. (2011). Instructional models for physical education, $3^{\text {rd }}$ edition, Scottsdale, Arizona: Holocomb Hathaway;

24. MORGAN, D. (2007). Paradigms Lost and Pragmatism Regained: Methodological Implications of Combining Qualitative and Quantitative Methods, Journal of Mixed Methods Research, 1(1): 48-76;

25. O'DONOGHUE, T. (2007). Planning your qualitative research project: An introduction to interpretivist research in education, London: Routledge;

26. PILL, S. (2013). Play with purpose. Hindmarsh, SA: Australian Council for Health, Physical Education and Recreation (ACHPER);

27. PILL, S. (2015). Using Appreciative Inquiry to explore Australian football coaches' experience with game sense coaching, Sport, Education and Society, 20(6): 799-818;

28. PILL, S. (2016). Implementing game sense coaching approach in Australian football through action-research, Agora para la educación física y el deporte, 18(1): 1-19;

29. PUNCH, K., \& OANCEA, A. (2009). Introduction to research methods in education, 2nd ed., Los Angeles: Ca: SAGE;

30. REID, P. (2003). More than a game? The role of sports governing bodies in the development of sport education programmes, European Physical Education Review, 9(3): 309-317;

31. SIOKOS, A. (2011). Determining the effectiveness of Small- Sided Football (SSF) implementation in metropolitan Association football, International Journal of Coaching Science, 5(1): 57-69;

32. WEIN, H. (2004). Developing game intelligence in soccer. Publisher: Reedswain Inc. 